\title{
Efeito do diâmetro e do comprimento das toras na secagem de lenha de um clone de Eucalyptus urophylla x Eucalyptus camaldulensis
}

\author{
Diameter and length effects of logs on firewood drying \\ clone of Eucalyptus urophylla x Eucalyptus camaldulensis
}

\author{
Christovão Pereira Abrahão ${ }^{1}$, Luiz César Silva Rocha ${ }^{2}$, \\ Heverton de Paula ${ }^{2}$, Edgard Geraldo Bertoli Trindade ${ }^{2}$, \\ Helder Bolognani Andrade ${ }^{3}$ e Reynaldo Campos Santana ${ }^{1}$
}

\begin{abstract}
Resumo
Este trabalho objetivou contribuir para a experiência em secagem de lenha para produção de carvão vegetal. Foi monitorada por 386 dias a secagem de toras de diferentes diâmetros e comprimentos dispostas inicialmente em pilhas no campo e transferidas para um pátio após 110 dias. Os teores de umidade médios determinados em base seca aos 47, 110, 182 e 386 dias foram 50,2\%, 33,2\%, 25,0\% e 16,3\% respectivamente. Aos 47 dias de secagem a madeira das toras de menor diâmetro, independente do comprimento, já se encontrava com umidade próxima ao ponto de saturação das fibras, enquanto que as toras de maior diâmetro ainda apresentavam teores de umidade em torno de $70 \%$. A influência do comprimento das toras sobre as taxas de secagem apresentou-se de forma diferente entre as duas classes de diâmetro.
\end{abstract}

Palavras-chave: Eucalipto; secagem ao ar; carvão vegetal.

\begin{abstract}
This work aimed to contribute to the experience in drying of wood for charcoal production. For 386 days, the drying of logs with different diameters and lengths laid initially in piles on the field and transferred to a drying yard after 110 was monitored. The average moisture contents determined in a dry basis at days 47 , 110,182 and 386 were $50.2 \%, 33.2 \%, 25.0 \%$ and $16.3 \%$, respectively. After 47 days of drying the smaller diameter logs, independently of the length, were already with moisture content near the fiber saturation point, while the larger diameter logs still presented moistures content around $70 \%$. The influence of the length of the logs over the drying rates was different between the two diameter classes.
\end{abstract}

Keywords: Eucalypts; air drying; vegetable charcoal.

\section{INTRODUÇÃO}

Nas carvoarias verticalizadas e que produzem em larga escala, muitas vezes, as datas das colheitas, os tempos de secagem, e a forma de empilhamento da lenha, além da logística da movimentação da madeira e do carvão vegetal dependem de fatores de ordem econômica e operacional.

A influência desses fatores externos à planta de carbonização, ou seja, fora do controle das empresas, pode levar à necessidade da adoção de práticas que resultem na utilização da madeira em condições abaixo do ideal em termos de umidade.

Segundo Vital et al. (1985) o teor de umidade da madeira é inversamente proporcional ao poder calorifico da madeira, e a qualidade do carvão vegetal produzido. Isso porque o rendimento e o tempo de carbonização são diretamente afetados, uma vez que toda a umidade será perdida na forma de vapor d'água durante o processo, o que exigirá uma maior quantidade de energia.

Muitos trabalhos envolvendo a modelagem da secagem natural da madeira são encontrados na literatura. Alguns deles foram conduzidos para madeira serrada (SIMPSON, 2004; SIMPSON; HART, 2000), ao passo que outros avaliaram a secagem de toras destinadas a diversas aplicações,

\footnotetext{
1Professor Adjunto do Departamento de Engenharia Florestal. UFVJM - Universidade Federal dos Vales do Jequitinhonha e Mucuri. Rodovia MGT 367 - KM583 - 39100-000 - Diamantina, MG, Brasil. E-mail: cabrahao@gmail.com

${ }^{2}$ Engenheiro Florestal pelo Departamento de Engenharia Florestal. UFVJM - Universidade Federal dos Vales do Jequitinhonha e Mucuri. Rodovia MGT 367 - KM583 - 39100-000 - Diamantina, MG, Brasil. E-mail: rochalcs.eng@gmail.com; heverton.floresta@gmail.com; edgardgbtrindade@gmail.com
}

${ }^{3}$ Diretor de P\&D. Vallourec. Rua Honduras, 78 - 35790-000 -Curvelo, MG, 35790-000 Curvelo, MG, Brasil. E-mail: helder@vmtubes.com.br 
Rodrigues et al. - Efeito do diâmetro e do comprimento das toras na secagem

de lenha de um clone de Eucalyptus urophylla x Eucalyptus camaldulensis

principalmente para a produção de carvão vegetal (REZENDE et al. 2010a e b; SIMPSON; WANG, 2003; STURION; TOMASELLI, 1990; VITAL et al. 1985). Nestes ficou evidenciada a influência do diâmetro das toras na taxa de secagem.

Rezende et al. (2010a) e Vital et al. (1985) constataram que o diâmetro tem influência direta na secagem natural da madeira, sendo observado que toras com um menor diâmetro apresentam uma taxa de secagem maior.

O comprimento das toras tornou-se uma variável de grande importância logística com a ampliação das dimensões dos fornos de carbonização retangulares, pois o carregamento mecanizado pode ser ainda acelerado ao se utilizarem toras mais longas. Entretanto, pouco se conhece sobre os efeitos do comprimento das toras na secagem da madeira e na qualidade do carvão.

Sendo necessária uma maior compreensão do processo de secagem da madeira, o objetivo do presente estudo é avaliar o efeito de duas classes diamétricas e do comprimento das toras na secagem natural de lenha de um clone hibrido Eucalyptus urophylla $\mathrm{x}$ Eucalyptus camaldulensis em condições industriais.

\section{MATERIAL E MÉTODOS}

\section{Local do experimento}

Foi utilizada madeira de um clone híbrido de Eucalyptus urophylla x Eucalyptus camaldulensis, com idade de sete anos, proveniente da empresa V\&M Florestal, de densidade básica média da madeira igual a $0,54 \mathrm{~g} / \mathrm{cm}^{3}$.

Os experimentos foram conduzidos na fazenda Itapoã, localizada no município de Paraopeba MG, a $19^{\circ} 18^{\prime} 11^{\prime \prime}$ de latitude Sul, 44 $30^{\prime} 17^{\prime \prime}$ de longitude Oeste. O clima da região é do tipo "Aw", segundo a classificação de Köepen, caracterizado como subtropical úmido, com verão chuvoso e estação seca de abril a setembro, com temperatura anual média de $20,9^{\circ} \mathrm{C}$ e precipitação média anual de $1.236 \mathrm{~mm}$ (RIBEIRO; WALTER, 1998). Durante o experimento, a umidade relativa do ar, a temperatura e a pluviosidade foram registradas em uma estação meteorológica instalada a cerca de 400 metros do local de estudo.

\section{Amostragem}

Em um talhão comercial com espaçamento 3 x 3 m, um trator florestal "Harvester" colheu, traçou e depositou em diferentes pilhas as toras, criando assim duas classes diamétricas. Os troncos foram traçados em toras de três comprimentos diferentes: 2,1, 3,7 e 5,0 metros.

Foram consideradas toras de diâmetro superior aquelas cujos diâmetros na base eram maiores ou iguais a $11 \mathrm{~cm}$, enquanto aquelas de diâmetro menor que $11 \mathrm{~cm}$, compuseram a classe de diâmetro inferior.

\section{Preparação das pilhas para secagem}

Imediatamente após a colheita das toras, foram montadas no campo, pilhas de seção transversal trapezoidal com base igual a 1,5 m e aproximadamente $0,5 \mathrm{~m}$ de altura. As pilhas permaneceram no talhão por 110 dias, quando as toras foram baldeadas para um pátio de secagem próximo à carvoaria, onde permaneceram por mais 275 dias arranjadas em pilhas de 3,0 m de altura e comprimento (seção transversal) variável, mantidos ainda individualizados os tratamentos. Na Figura 1 encontra-se o fluxograma das operações e a disposição das pilhas.

\section{Determinação da umidade}

Para determinação da umidade inicial da madeira, no momento da colheita foram separadas 10 toras de cada tratamento, das quais foram extraídos discos à metade de seus comprimentos. A umidade dos discos foi determinada pelo método gravimétrico.

As amostragens para acompanhamento da umidade da madeira de cada tratamento foram realizadas aos 47, 110, 182 e aos 386 dias de secagem, e em todas as etapas foram escolhidas aleatoriamente 27 toras de cada tratamento. As amostras para determinação da umidade foram constituídas de serragem retirada com o uso de uma furadeira portátil operando à baixa rotação com broca de 8 $\mathrm{mm}$ de diâmetro. As perfurações transpassavam o centro das toras e foram feitas a $25 \%$ do comprimento, tomando-se como base o maior diâmetro das toras. 


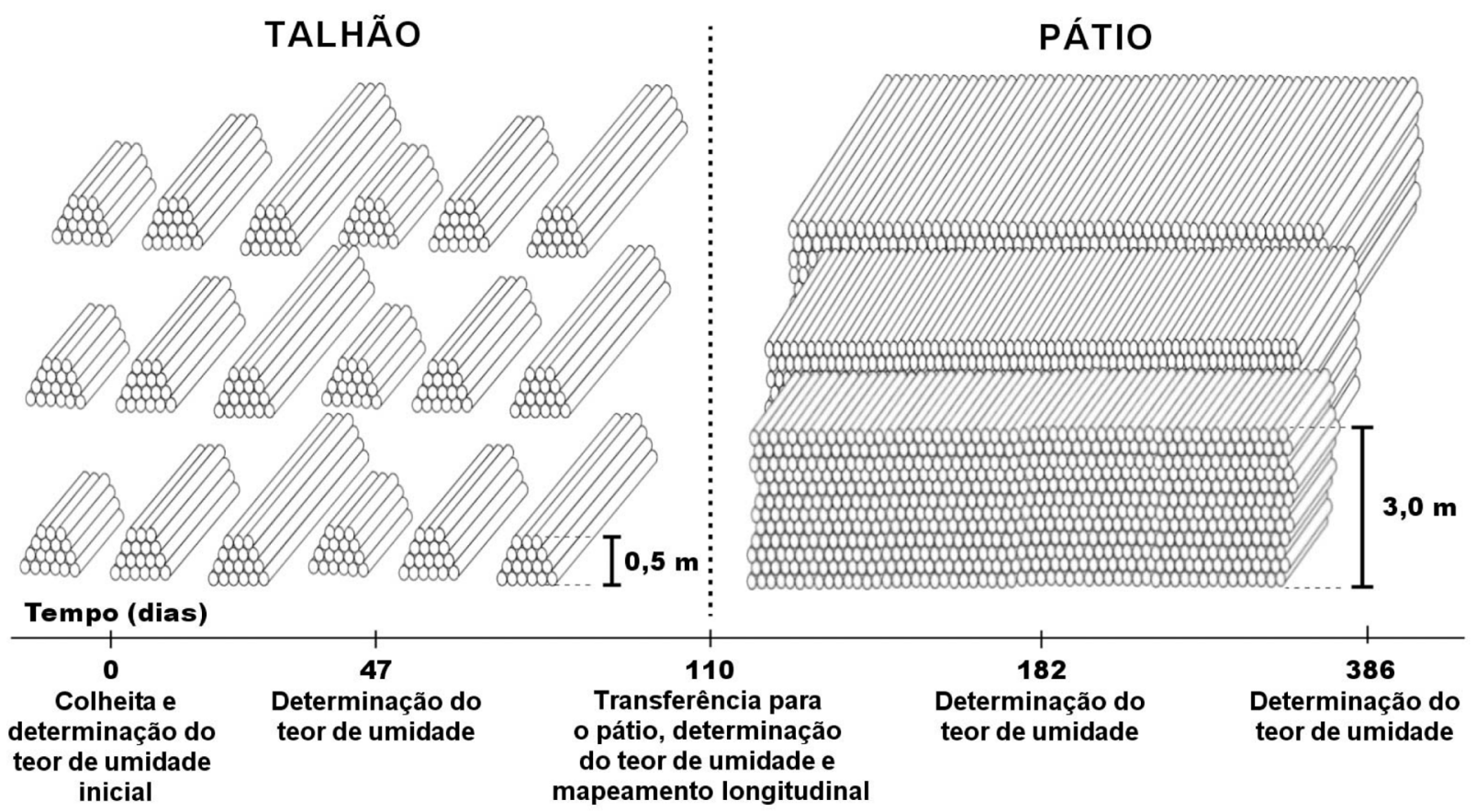

Figura 1. Etapas de condicionamento evidenciando as alturas das pilhas em cada etapa e o tempo em dias para a realização das medições.

Figure 1. Steps of conditioning emphasizing the heights of the piles in each step and time, in days, of the measurements.

A umidade das amostras foi medida em balança determinadora de umidade, corrigida pela expressão Ubs_corrigida $=0,79$ x Ubs_observada $+4,98$. Esta expressão foi desenvolvida pela própria empresa para a madeira em estudo com o ajuste de um modelo de calibração que apresentou $\mathrm{R}^{2}=$ 0,98 e erro padrão da estimativa de 1,6\% de umidade (V\&M Florestal, 2010).

Ao 110 dias foi realizado também um estudo sobre a distribuição da umidade ao longo do comprimento das toras. Para tanto foram selecionadas nove toras de cada tratamento e destas foram retiradas amostras da madeira por perfuração em dez pontos equidistantes. Então foram comparadas as médias e a variabilidade da umidade em cada ponto entre as classes de comprimento e diâmetro.

Foram também calculadas as taxas de secagem para cada tratamento entre as etapas de amostragem, dividindo-se a diferença entre as umidades médias de etapas antecedentes pelo intervalo entre estas etapas subsequentes.

\section{Análise estatística}

As combinações entre os três comprimentos e as duas classes diamétricas das toras resultaram em seis tratamentos.

Os dados para os teores de umidade de cada tratamento nas diferentes datas de medição, bem como os provenientes do mapeamento da umidade ao longo do tronco, foram submetidos à análise de variância e as médias comparadas pelo teste de Scheffé.

Inicialmente foram comparadas as médias entre o teor de umidade de todos os tratamentos agrupados por tempo de secagem. Posteriormente, foram comparadas as médias de cada tratamento dentro de cada tempo, com o objetivo de se verificar o efeito de cada fator de variação e suas interações.

Para todos os testes estatísticos utilizados empregou-se o nível de significância de 5\%.

\section{RESULTADOS E DISCUSSÃO}

A umidade inicial média para as toras de maior e menor diâmetro mostraram-se iguais estatisticamente e, quando agrupados os valores das duas classes diamétricas, estes apresentaram distribuição normal com média igual a 78,4\% e desvio padrão igual a 5,3\%. 
Na Figura 2 são apresentados os histogramas para os valores do teor de umidade, suas médias e coeficientes de variação aos 47, 110, 182 e 386 dias de secagem, agrupando-se os tratamentos (combinações entre classes de comprimentos e diâmetros) observa-se uma dinâmica na secagem de acordo com o esperado para lotes de toras de diâmetros heterogêneos. A evolução da forma dos histogramas para o teor de umidade ao longo do tempo de exposição ao ar indica a migração constante de toras de umidade mais alta para categorias mais secas.

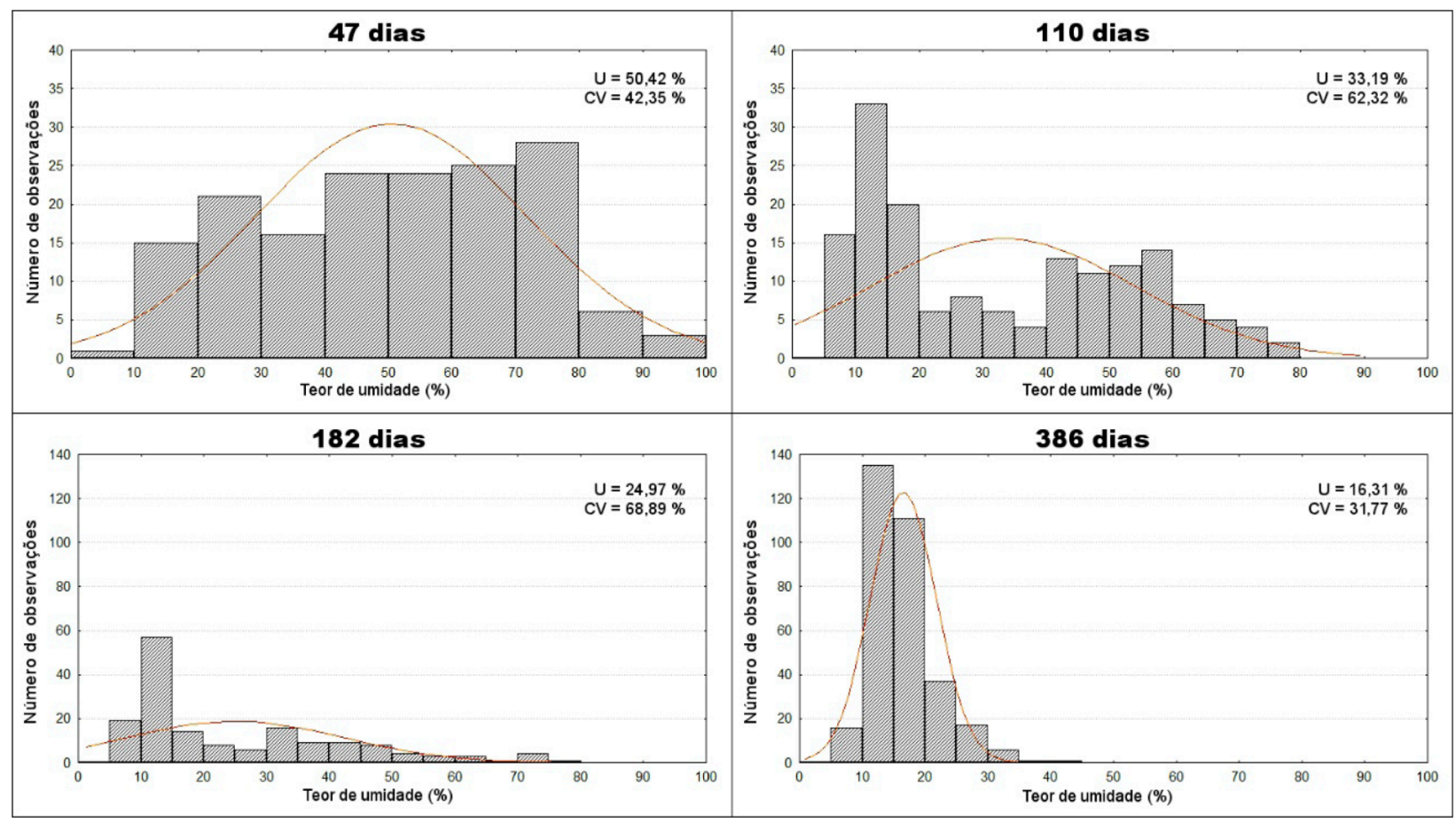

Figura 2. Histogramas, valores médios (U) e coeficientes de variação (CV) para o teor de umidade aos 47, 110, 182 e 386 dias de secagem, agrupando-se as toras dos diferentes comprimentos e diâmetros. As médias para $U$ em cada tempo de secagem apresentam diferenças significativas. A linha contínua representa a distribuição normal esperada para a mesma média e variância para o teor de umidade naquele estágio.

Figure 2. Histograms, mean values (U) and coefficients of variation (CV) for the moisture content at $47,110,182$ and 386 days of drying, grouping the logs of the different lengths and diameters. The means for $U$ at each time of drying showed significant differences. The solid line represents the expected normal distribution for the same mean and variance of the moisture content at that stage.

Houve diferença significativa entre os valores médios do teor de umidade, que vão caindo continuamente, enquanto o coeficiente de variação sofre elevação com posterior queda à medida que se aumenta o tempo de secagem.

Assim, logo aos 47 dias, percebe-se uma ligeira distinção entre amostras mais úmidas e mais secas, devido à menor velocidade de secagem apresentada pelas toras de diâmetro maior. Esta distinção acentua-se aos 110 dias, quando as populações de diferentes diâmetros (e teores de umidade) encontram-se bem separadas. Aos 182 dias, o pico das categorias de maior umidade é rebaixado, já que partes das toras de maior diâmetro se encontram mais secas. Após 386 dias, possivelmente houve tempo suficiente para que grande parte do material chegasse ao equilíbrio higroscópico, apresentando-se os valores concentrados em torno da média.

Aos 47 dias de secagem a média geral para o teor de umidade (50\%) foi inferior àquelas apresentadas por Rezende et al. (2010b) para a madeira de E. urophylla (70\%) e por Vital et al. (1985) para a madeira de E. grandis (70\%) e superior a que foi relatada por Rezende et al. (2010a) para a madeira de E. grandis (35\%), submetidas à secagem ao ar pelo mesmo período. Note-se que estes autores estudaram a secagem de toras de diferentes distribuições diamétricas sob diferentes condições climáticas e de empilhamento.

A Tabela 1 apresenta, para cada tempo de secagem, um resumo da análise de variância, as médias para o teor de umidade por classe de comprimento, as médias e a variabilidade para cada tratamento, além da plotagem destas últimas médias. Em todos os tempos de secagem houve efeito significativo do comprimento e do diâmetro, porém somente para o tempo de 182 dias foi detectado um efeito significativo para a interação comprimento x diâmetro. O efeito do diâmetro sobre o teor de 
umidade mostrou-se consistente em todas as etapas da secagem. Assim, toras de maior diâmetro, independente do comprimento, sempre se encontravam mais úmidas, por isso e por simplicidade na exposição, somente os efeitos do comprimento e da interação, os quais variaram entre as etapas, foram apresentados nos desdobramentos da análise de variância.

Tabela 1. Resumo da análise de variância, valores médios e coeficiente de variação para o teor de umidade da madeira dos diferentes tratamentos em cada tempo de secagem. Dentro do mesmo tempo de secagem, médias seguidas da mesma letra são iguais pelo teste de Scheffé. $C$ - classes de comprimento $(C 1=2,1$ $\mathrm{m} ; \mathrm{C} 2=3,7 \mathrm{~m} ; \mathrm{C} 3=5,0 \mathrm{~m})$. $\mathrm{D}$ - classes de diâmetro (D1 $<11 \mathrm{~cm} ; \mathrm{D} 2 \geq 11 \mathrm{~cm}$ ). Os valores de $\mathrm{F}$ marcados com asterisco são significativos.

Table 1. Analysis of variance summary, mean values and coefficients of variation for the moisture content of the wood of the different treatments at each drying time. At the same drying time, means followed by the same letter as equal by Sheffé's test. $C$ - length classes $(C 1=2.1 \mathrm{~m} ; C 2=3.7 \mathrm{~m} ; \mathrm{C} 3=5.0 \mathrm{~m})$. D - diameter classes (D1 < $11 \mathrm{~cm} ; \mathrm{D} 2 \geq 11 \mathrm{~cm}$ ). The $\mathrm{F}$ values marked with an asterisk are significant.

\begin{tabular}{|c|c|c|c|c|c|c|c|c|c|c|c|}
\hline & \multirow{2}{*}{$\begin{array}{c}\text { Tempo } \\
\text { (dias) }\end{array}$} & \multicolumn{3}{|c|}{ Análise de variância } & \multirow[b]{2}{*}{$\begin{array}{l}\text { Compri- } \\
\text { mento (m) }\end{array}$} & \multirow[b]{2}{*}{$\begin{array}{l}\text { Diâme- } \\
\text { tro }(\mathbf{c m})\end{array}$} & \multicolumn{3}{|c|}{ Teor de umidade } & \multirow{2}{*}{\multicolumn{2}{|c|}{$\begin{array}{c}\text { Plotagem das médias } \\
\qquad \because-\mathrm{D} 1 \\
\rightarrow-\mathrm{D} 2\end{array}$}} \\
\hline & & $\begin{array}{c}\text { Fontes de } \\
\text { variação }\end{array}$ & & $\begin{array}{l}\text { statísti- } \\
\text { cas }\end{array}$ & & & $\begin{array}{c}\text { Média } \\
(\%)\end{array}$ & $\begin{array}{c}\text { Média } \\
(\%)\end{array}$ & $\begin{array}{l}\text { CV } \\
(\%)\end{array}$ & & \\
\hline \multirow{12}{*}{$\begin{array}{l}\text { Secagem } \\
\text { no Talhão }\end{array}$} & \multirow{6}{*}{47} & \multirow{2}{*}{ C } & $F$ & $24,3^{*}$ & \multirow{2}{*}{2,1} & $<11$ & \multirow{2}{*}{$48,1 \mathrm{a}$} & $32,2 a b$ & 49,3 & \multirow{4}{*}{$\begin{array}{l}100 \\
\stackrel{\overbrace{}}{\partial} 50\end{array}$} & \\
\hline & & & $p$ & 0 & & $\geq 11$ & & $64,0 \mathrm{c}$ & 19,8 & & \\
\hline & & $\mathrm{D}$ & $\mathrm{F}$ & $361,9^{*}$ & 37 & $<11$ & $590 \mathrm{~b}$ & $43,7 \mathrm{~b}$ & 21,7 & & \\
\hline & & & $\mathrm{p}$ & 0 & 3,1 & $\geq 11$ & $59,0 \mathrm{D}$ & $74,1 \mathrm{c}$ & 13,4 & & \\
\hline & & \multirow{2}{*}{$C \times D$} & $F$ & 2,7 & \multirow{2}{*}{5} & $<11$ & \multirow{2}{*}{44,3 a } & $24,3 a$ & 33,4 & \multirow[t]{2}{*}{0} & \\
\hline & & & $\mathrm{p}$ & 0,07 & & $\geq 11$ & & $64,1 \mathrm{c}$ & 16,7 & & 3 \\
\hline & \multirow{6}{*}{110} & \multirow{2}{*}{ C } & $F$ & $5,6^{*}$ & \multirow{2}{*}{2,1} & $<11$ & \multirow{2}{*}{39,3 a } & $24,7 a$ & 53,8 & \multirow{4}{*}{$\begin{array}{r}60 \\
\overbrace{5} \\
5\end{array}$} & \\
\hline & & & $p$ & 0 & & $\geq 11$ & & $54,5 b$ & 23,9 & & \\
\hline & & ח & $F$ & $233,8^{*}$ & 37 & $<11$ & 3810 & $22,2 a$ & 73,7 & & \\
\hline & & U & $p$ & 0 & $3, I$ & $\geq 11$ & 30,1 a & $53,9 b$ & 25,0 & & \\
\hline & & \multirow{2}{*}{$C \times D$} & $\mathrm{~F}$ & 1,1 & \multirow{2}{*}{5} & $<11$ & \multirow{2}{*}{$31,1 \mathrm{~b}$} & $12,7 a$ & 61,7 & \multirow{2}{*}{$0^{-}$} & \\
\hline & & & $p$ & 0,34 & & $\geq 11$ & & $49,5 b$ & 26,7 & & $\mathrm{C} 1 \mathrm{C} 2 \mathrm{C} 3$ \\
\hline \multirow{12}{*}{$\begin{array}{l}\text { Secagem } \\
\text { no Pátio }\end{array}$} & \multirow{6}{*}{182} & \multirow{2}{*}{$\mathrm{C}$} & $F$ & $9,7^{*}$ & \multirow{2}{*}{2,1} & $<11$ & \multirow{2}{*}{$22,7 \mathrm{a}$} & $13,2 a$ & 39,6 & 60 . & \\
\hline & & & $p$ & 0 & & $\geq 11$ & & $32,2 \mathrm{bc}$ & 31,5 & & \\
\hline & & م & $F$ & $260,2^{*}$ & 37 & $<11$ & 3150 & $16,7 a b$ & 54,1 & & \\
\hline & & U & $\mathrm{p}$ & 0 & $3, I$ & $\geq 11$ & $31,0 \mathrm{~d}$ & $46,2 \mathrm{c}$ & 32,3 & & \\
\hline & & $\mathrm{C} \times \mathrm{D}$ & $F$ & $5,4^{*}$ & 5 & $<11$ & $294 \mathrm{~h}$ & $13,1 a$ & 43,4 & 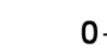 & \\
\hline & & $C \times D$ & $p$ & 0 & 5 & $\geq 11$ & $\angle 9,4 D$ & $45,5 \mathrm{c}$ & 33,9 & & $\mathrm{C} 1 \mathrm{C} 2 \mathrm{C} 3$ \\
\hline & & C & $F$ & $8,2^{*}$ & 21 & $<11$ & 67 & $15,1 a$ & 28,6 & 20 & 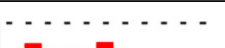 \\
\hline & & C & $p$ & 0 & 2,1 & $\geq 11$ & $10,1 \mathrm{a}$ & $18,2 a$ & 30,8 & & \\
\hline & 386 & $D$ & $\mathrm{~F}$ & $10,2^{*}$ & 37 & $<11$ & 179 a & $17,6 a$ & 35,1 & ङ 15 & \\
\hline & & U & $\mathrm{p}$ & 0 & $3, I$ & $\geq 11$ & $17,9 \mathrm{~d}$ & $18,2 a$ & 30,0 & & \\
\hline & & $C \times D$ & $\mathrm{~F}$ & 1,6 & 5 & $<11$ & $153 \mathrm{~b}$ & $14,2 a$ & 26,2 & $10^{-1}$ & \\
\hline & & $4 \times 5$ & $p$ & 0,20 & $J$ & $\geq 11$ & $15,3 \mathrm{D}$ & $16,2 a$ & 25,6 & & $\mathrm{C} 1 \mathrm{C} 2 \mathrm{C} 3$ \\
\hline
\end{tabular}

Aos 47 dias de secagem, as toras de maior diâmetro, independente do comprimento, apresentaram teores de umidade iguais entre si e maiores que as de menor diâmetro. Neste momento, entre as toras de menor diâmetro, aquelas de 3,7 $\mathrm{m}$ de comprimento continham uma quantidade de água estatisticamente equivalente àquelas de 2,1 m e superior às de 5,0 m.

Após 110 dias de secagem, se estabelece uma grande diferença entre as toras de maior e menor diâmetro, independente de seu comprimento. Já aos 182 dias, as toras de maior diâmetro e comprimento igual a $2,1 \mathrm{~m}$ atingiram teor de umidade igual ao daquelas de menor diâmetro e comprimento igual a 3,7 m, enquanto que as de maior diâmetro e 5,0 m de comprimento mantiveram-se igualmente mais úmidas que as demais. Ao final dos 386 dias, todos os tratamentos apresentaram teores de umidade estatisticamente iguais.

De forma geral, os coeficientes de variação para o teor de umidade das toras de menor diâmetro apresentaram-se mais altos e seus valores atingiram um máximo aos 110 dias, caindo nas duas avaliações posteriores. As toras de maior diâmetro, por sua vez, tiveram sua variabilidade máxima observada aos 182 dias, vindo também a cair ligeiramente aos 386 dias.

A Figura 3 apresenta as taxas de secagem observadas para os diferentes tratamentos, nos diferentes tempos de medição. A exceção do tratamento que combina toras de maior diâmetro e 3,7 m de comprimento, as taxas mais altas foram observadas nos primeiros 47 dias de secagem. 


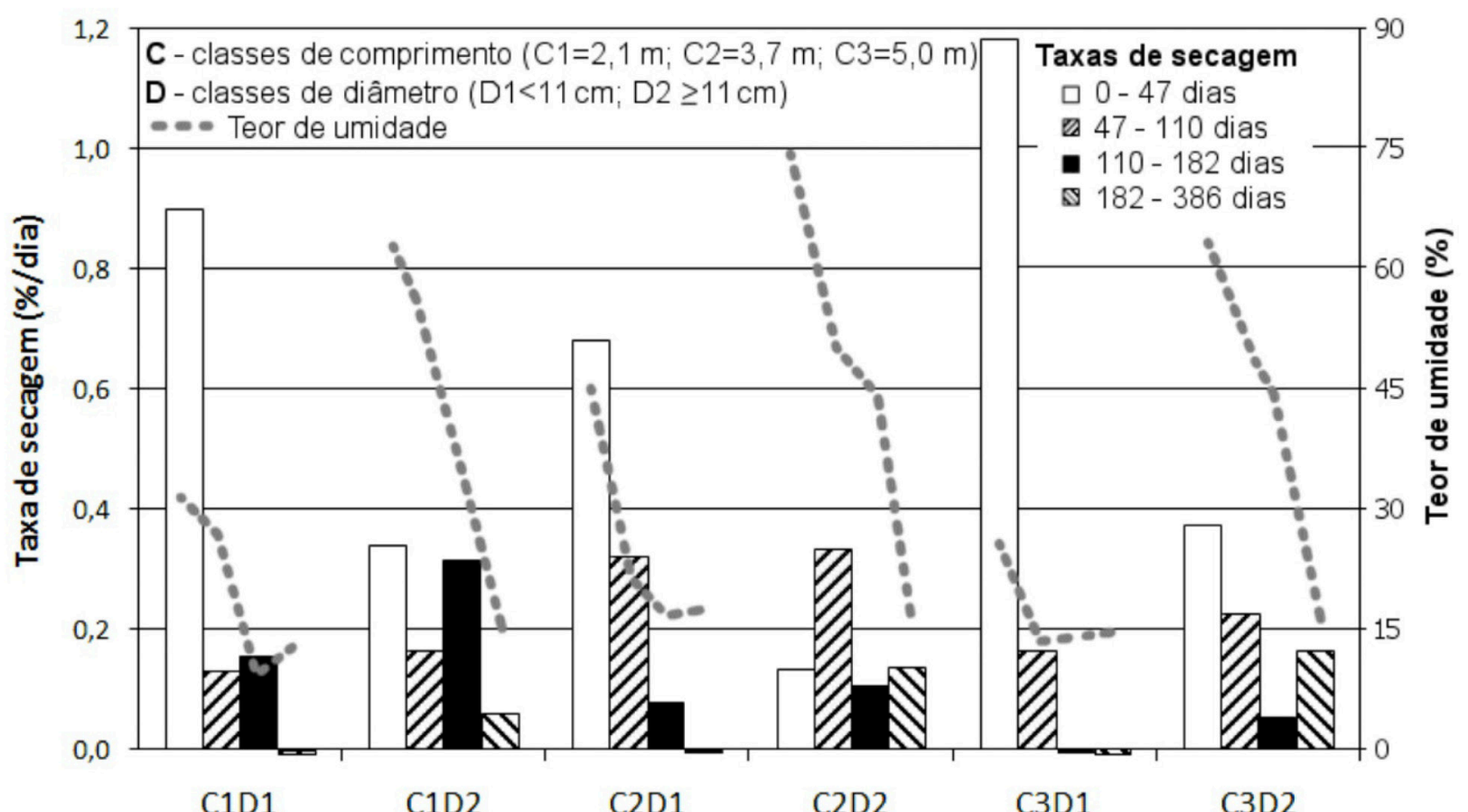

Figura 3. Taxas de secagem e teor de umidade para os seis tratamentos ao longo das etapas de secagem. $\mathrm{O}$ teor de umidade foi determinado ao final de cada etapa.

Figure 3. Drying rates and moisture content for the six treatments throughout the drying stages. The moisture content was determined at the end of each stage.

As altas taxas de secagem observadas para as toras de menor diâmetro no período inicial de exposição ( 0 a 47 dias) podem ser explicadas pela combinação entre o menor percurso radial para a saída da água livre e a menor energia requerida para a sua movimentação, como observaram Vital et al. (1985). Soma-se a estes fatores a maior permeabilidade da madeira destas toras conferida pela maior proporção de alburno das regiões mais altas nos troncos de árvores do gênero Eucalyptus, como descrito por Oliveira et al. (1999).

Este efeito foi ainda mais acentuado no tratamento que continha toras de menor diâmetro e 5,0 $\mathrm{m}$ de comprimento, pois se considerada a conicidade média de $0,9 \mathrm{~cm} / \mathrm{m}$ (OLIVEIRA et al. 1999), as extremidades superiores destas toras poderiam apresentar diâmetros inferiores a 3,0 cm.

Somente o tratamento que combinava toras de maior diâmetro e comprimento de 3,7 m apresentou uma taxa de secagem inicial ( 0 a 47 dias) inferior à subseqüente. Este fato pode ser explicado em parte pelo efeito do comprimento sobre o percentual de alburno nestas toras, o qual não foi tão expressivo quanto para as toras de 5,0 m. Porém, há que se considerar o efeito do comprimento no alongamento da distância a ser percorrido pela água no sentido axial. Também deve ser levado em conta um possível arranjo das pilhas deste tratamento no campo que tenha sido desfavorável à secagem inicial, como sua orientação em relação à insolação e ao vento, além do grau de compactação da pilha e situação no relevo. Tais condições adversas podem ter sido superadas na segunda etapa da secagem (47 a 110 dias) com o aumento da temperatura e queda da umidade relativa do ar, o que acarretou elevação da taxa de secagem neste tratamento, neste período.

Aos 182 dias de secagem, todos os tratamentos que continham toras de menor diâmetro apresentaram teores de umidade médios satisfatoriamente baixos, enquanto que as toras de maior diâmetro ainda encontravam-se acima do ponto de saturação das fibras. Uma exceção a isto foi o tratamento que combinava toras de maior diâmetro e comprimento igual a 2,1 m, cuja média para o teor de umidade foi classificada como sendo estatisticamente igual àquelas das toras de menor diâmetro e 3,7 m de comprimento, enquanto que as médias para as toras de maior diâmetro e maiores comprimentos mantiveram-se iguais num patamar superior.

Na prática, tal efeito pode ser questionado se consideradas a elevada diferença entre as médias (32,3\% e 16,7 \%) e a magnitude dos coeficientes de variação (31,5\% e 54,1\%).

Ao final dos 386 dias de secagem todos os tratamentos atingiram teores de umidade abaixo de 
20\%. Em alguns casos notaram-se ganhos de umidade, o que pode ser justificado pela exposição do material às condições de alta umidade relativa do ar e precipitação que ocorreram no final da última etapa.

Na Figura 4 são apresentadas as médias para as taxas de secagem agrupando-se todos os tratamentos, sobrepostas às condições de temperatura e umidade relativa do ar durante os 382 dias de monitoramento. Mesmo agrupando-se os tratamentos, a taxa de secagem dos primeiros 47 dias mantém-se destacada em um patamar muito superior.

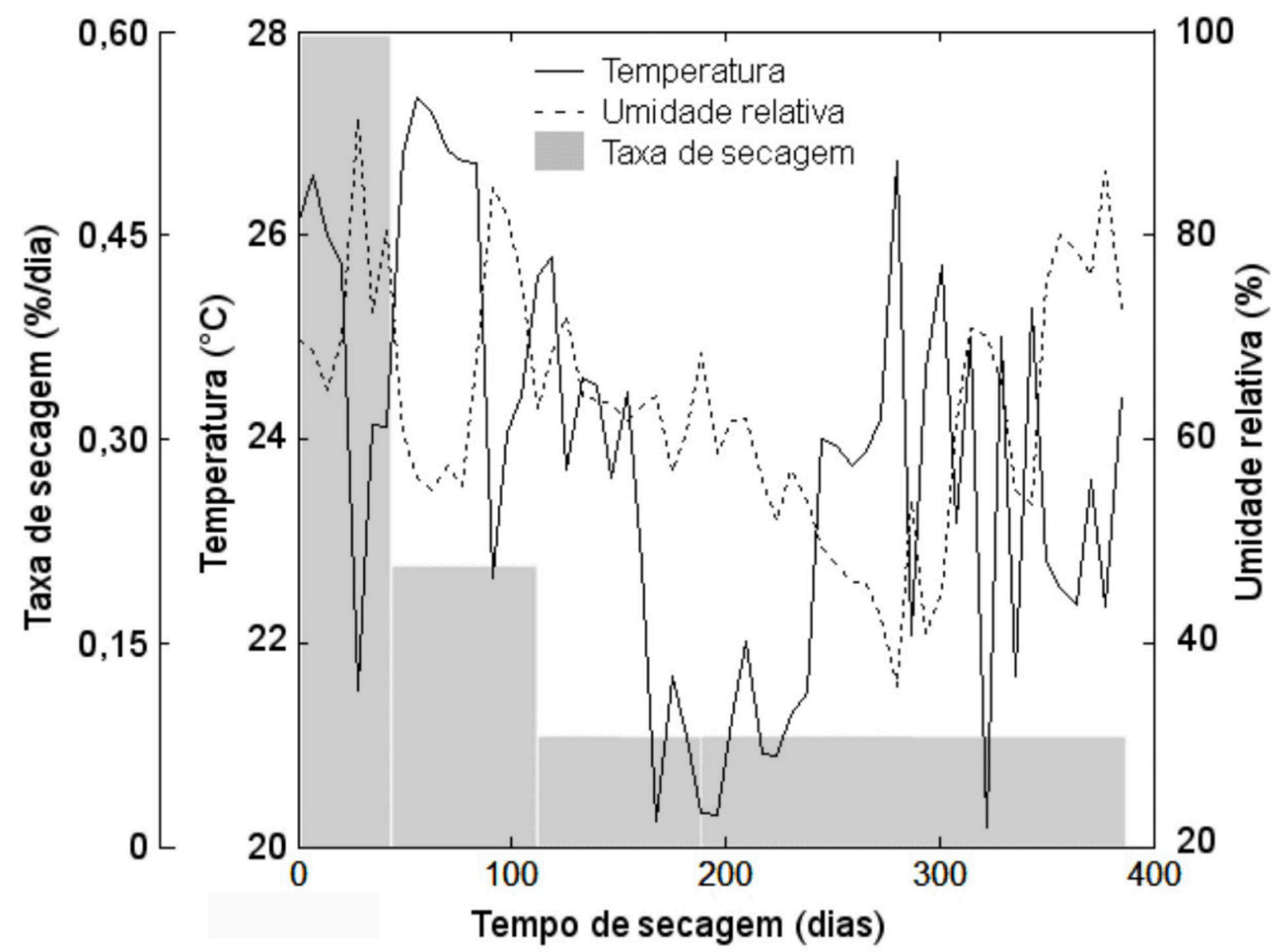

Figura 4. Taxas de secagem médias para os seis tratamentos e médias semanais para a temperatura e a umidade relativa do ar ao longo das etapas de secagem.

Figure 4. Average drying rates for the six treatments and weekly means for the temperature and air relative humidity throughout the drying stages.

Os resultados para o mapeamento do teor de umidade ao longo do comprimento das toras aos 107 dias são apresentados na Figura 5. À exceção dos tratamentos que combinam toras de menor diâmetro e comprimentos de 2,1 m e 5,0 m, observaram-se maiores teores de umidade nas porções intermediárias dos comprimentos. No caso das toras de maior diâmetro e comprimento igual a 5,0 m, há uma correlação negativa e significativa entre o teor de umidade e a distância da extremidade basal.

Aos 110 dias de secagem evidenciou que, para as toras de maior diâmetro, independente do comprimento, o teor de umidade era mais baixo nas extremidades basais, subindo até os $20 \%$ do comprimento e permanecendo aproximadamente constante até $60-70 \%$ do comprimento e, a partir daí, voltava a cair até as extremidades de menor diâmetro. Esta assimetria pode ser associada à conicidade das toras e ao efeito da posição base-topo no teor de alburno e, por consequência, na permeabilidade da madeira, como já referido anteriormente.

Ao se comparar a variação do teor de umidade ao longo do comprimento das toras de menor diâmetro e diferentes comprimentos não se detectou um padrão definido. Nas toras de 2,0 m de comprimento as extremidades e o centro resultaram mais úmidos; as toras de 3,7 m exibiram um comportamento similar àquelas de maior diâmetro, ou seja, o centro mais úmido que as extremidades; já nas toras de 5,0 m, a umidade se manteve mais alta desde a extremidade basal até a metade 
do comprimento, caindo a partir daí em direção a extremidade de menor diâmetro. É possível que a ausência de um padrão na variação longitudinal do teor de umidade das toras de menor diâmetro esteja associada à sua maior susceptibilidade às influências ambientais, uma vez que suas reduzidas dimensões transversais e sua maior permeabilidade facilitam as interações com o meio externo, permitindo que respondam rapidamente às pequenas variações de umidade e temperatura do ar no interior da pilha. Esta última observação parece ser também corroborada pelos elevados coeficientes de variação relatados na Tabela 1 para as toras de menor diâmetro aos 110 dias de secagem.

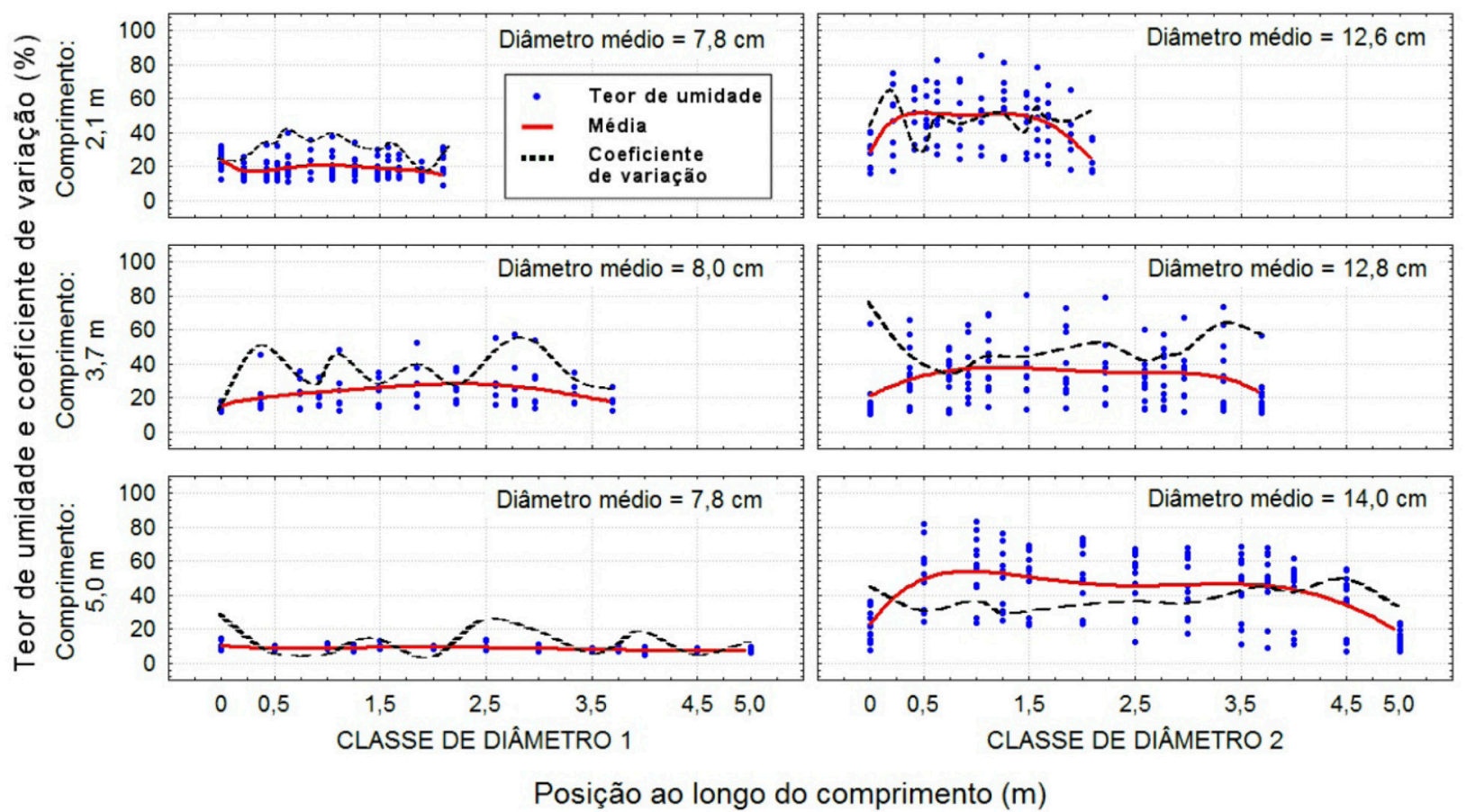

Figura 5. Teor de umidade e seu coeficiente de variação ao longo do comprimento das toras de diferentes classes de diâmetro e comprimento após 110 dias de secagem no talhão.

Figure 5. Moisture content and its coefficient of variation along the length of the logs of different diameter and length classes after 110 days of drying on the field.

Cabe ainda ressaltar que a não permanência de pilhas testemunhas no talhão tornou impossível avaliar se a transferência das toras para o pátio afetou a secagem de alguma forma, pois variações nas taxas de secagem ao longo do processo são esperadas mesmo mantendo-se constantes as condições ambientais, já que a natureza das interações entre a água e a madeira, bem como os coeficientes de difusão do vapor d'água, também variam com o próprio teor de umidade e seus gradientes no interior das peças (SIAU, 1984; STAMM, 1964).

\section{CONCLUSÕES}

Aos 47 dias de secagem a madeira das toras de menor diâmetro, independente do comprimento, já se encontrava com umidade próxima ao ponto de saturação das fibras, enquanto que as toras de maior diâmetro ainda apresentavam teores de umidade em torno de 70\%.

Nas toras de maior diâmetro, aquelas de menor comprimento apresentaram taxas de secagem médias mais altas, ao passo que, entre as toras de maior diâmetro, aquelas de maior comprimento secaram mais rápido, seguidas pelas de menor comprimento.

\section{REFERÊNCIAS BIBLIOGRÁFICAS}

OLIVEIRA, J. T. S.; HELLMEISTER, J. C.; SIMÕES, J. W.; TOMAZELLO FILHO, M. Caracterização da madeira de sete espécies de eucaliptos para a construção civil: 1 - avaliações dendrométricas das árvores. Scientia Forestalis, Piracicaba. n. 56, p. 113-124, dez. 1999. 
REZENDE, R. N.; LIMA, J. T.; PAULA, L. E. R.; FARIA, A. L. R. Secagem ao ar livre de toras de Eucalyptus grandis em Lavras, MG. Cerne, Lavras, v. 16, Suplemento, p. 41-47, jul. 2010a.

REZENDE, R. N.; LIMA, J. T.; SILVA, J. R. M.; NAPOLI, A.; ANDRADE, H. B.; FARIA, A. L. M. Air drying of logs from na Eucalyptus urophylla clone for carbonization use. Cerne, Lavras, v. 16, n. 4, p. 565-572, out./dez. 2010b.

RIBEIRO, J. F.; WALTER, B. M. T. Fitofisionomias do bioma Cerrado. In: SANO, S. M.; ALMEIDA, S. P. (Ed.). Cerrado ambiente e flora. Planaltina: EMBRAPA-Cerrados, 1998. p. 89-166.

SIAU, J. F. Transport processes in wood. New York: Springer-Verlag, 1984. 245 p.

SIMPSON, W. T. Estimating air drying times of lumber with multiple regression. Madison: USDA Forest Service, 2004. 6 p. (FPL Research Note, 293).

SIMPSON, W. T.; HART, C. A. Estimates of air drying times for several hardwoods and softwoods. Madison: USDA Forest Service, 2000. 70 p. (FPL General Technical Report, 21).

SIMPSON, W. T.; WANG, X. Estimating air drying times of small-diameter ponderosa pine and Douglas-fir logs. Madison, USDA Forest Service, 2003. 14 p. (PFL Research Paper, 613).

STAMM, A. J. Wood and cellulose science. New York: Ronald Press, 1964. 549 p.

STEIN, F. R. Avaliação técnica do tempo de estocagem da madeira. Viçosa: UFV, 2003. 36 p. (Monografia)

STURION J. A.; TOMASELLI I. Influência do tempo de estocagem de lenha de bracatinga na produção de energia. Boletim de Pesquisa Florestal, Colombo, n. 21, p. 37-47, dez. 1990.

VITAL, B. R.; DELLA LUCIA, R. M.; VALENTE, O. F. Estimativa do teor de umidade de lenha para carvão em função do tempo de secagem. Revista Árvore, Viçosa. v. 9, n. 1, p. 10-27, 1985.

V\&M FLORESTAL. Secagem natural da madeira no campo para produção de carvão vegetal. In: FÓRUM NACIONAL SOBRE CARVÃO VEGETAL, 2, 2010, Sete Lagoas, Anais... Sete Lagoas: SIF-UFV, 2010.

Recebido em 01/10/2014

Aceito para publicação em 14/07/2015

Sci. For., Piracicaba, v. 44, n. 109, p. 85-93, mar. 2016

DOI: dx.doi.org/10.18671/scifor.v44n109.08 
